\title{
Comparison of alternative soil particle-size distribution models and their correlation with soil physical attributes
}

\author{
Fatemeh Afrasiabi ${ }^{1}$, Habib Khodaverdiloo $^{1 *}$, Farrokh Asadzadeh ${ }^{1}$, Martinus Th. van Genuchten ${ }^{2,3}$ \\ ${ }^{1}$ Department of Soil Science, Urmia University, Urmia 57135-165, Iran. \\ ${ }^{2}$ Department of Earth Sciences, Utrecht University, Utrecht, Netherlands. \\ ${ }^{3}$ Center for Environmental Studies, CEA, São Paulo State University, UNESP, Rio Claro, SP, Brazil. \\ * Corresponding author. E-mail: h.khodaverdiloo@urmia.ac.ir
}

\begin{abstract}
Complete descriptions of the particle-size distribution (PSD) curve should provide more information about various soil properties as opposed to only the textural composition (sand, silt and clay (SSC) fractions). We evaluated the performance of 19 models describing PSD data of soils using a range of efficiency criteria. While different criteria produced different rankings of the models, six of the 19 models consistently performed the best. Mean errors of the six models were found to depend on the particle diameter, with larger error percentages occurring in the smaller size range. Neither SSC nor the geometric mean diameter and its standard deviation correlated significantly with the saturated hydraulic conductivity $\left(K_{f s}\right)$; however, the parameters of several PSD models showed significant correlation with $K_{f s}$. Porosity, mean weight diameter of the aggregates, and bulk density also showed significant correlations with PSD model parameters. Results of this study are promising for developing more accurate pedotransfer functions.
\end{abstract}

Keywords: Lake Urmia (Iran); Particle-size distribution models; Pedotransfer functions; Soil physical properties.

\section{INTRODUCTION}

The particle-size distribution (PSD) is a fundamental physical property of soils. Knowing the soil PSD is critical for a range of hydrological, geological, agricultural, and geotechnical applications, including soil classification, as summarized well by Bayat et al. (2015). For example, the soil PSD is widely used to estimate such key soil attributes as infiltration (e.g., Ghorbani-Dashtaki et al., 2016; Parchami-Araghi et al., 2013), the saturated hydraulic conductivity (Jabro, 1992; Saxton et al., 1986), soil water retention (Arya and Paris, 1981; Ghorbani Dashtaki et al., 2010; Khodaverdiloo et al., 2011) and movement (Nemes et al., 2003), soil erosion (Beke et al., 1989; Xu et al., 2013), the cation exchange capacity of soils (Ersahin et al., 2006; Liao et al., 2015; Manrique et al., 1991) and various chemical sorption parameters of soils (Khodaverdiloo and Samadi, 2011).

Predictions of many soil properties and functions often need more detailed soil textural data than only the sand, silt and clay (SSC) fractions. Therefore, many studies were undertaken to provide more detail regarding the soil PSD. For example, Shirazi and Boersma (1984) and Shirazi et al. (1988) transformed the standard textural triangle into a new diagram based on mean particle size and standard deviations of particle size to provide greater resolution in detecting classified soils within a textural class. Accordingly, parameters other than SSC are often used to reflect the soil PSD in various predictive functions (e.g. Ghorbani Dashtaki et al., 2010). Examples are the geometric mean diameter $\left(d_{g}\right)$ and its standard deviation $\left(\sigma_{g}\right)$, the coefficient of uniformity $\left(C_{u}\right)$, the coefficient of curvature $\left(C_{c}\right)$, and the diameter of soil particles having a specific percentage of smaller particles (e.g., $\mathrm{D}_{10}, \mathrm{D}_{30}, \mathrm{D}_{50}, \mathrm{D}_{60}$, etc.), which then may serve as measures of soil gradation or other properties. Mathematically representing PSD data hence provides several benefits in soil mechanics, physics, hydrodynamic and geotechnical applications (Fredlund et al., 2000), as well as helps to convert PSD data of various particle-size classification systems to the desired formulation (Nemes et al., 1999; Skaggs et al., 2001). These applications require the definition of complete PSD curves using some mathematical model that best fits experimental data.

Consequently, various equations have been introduced over the years to describe the soil PSD, each of which often has its own specific advantages and limitations (Bayat et al., 2015; Fredlund et al., 2000). A careful selection of the most appropriate PSD model may have a significant impact on the estimated soil particle distribution density at a given particle size (Nemes et al., 1999) and hence is important to more precisely estimate soil properties (e.g., Bittelli et al., 1999; Hwang and Powers, 2003). Several studies have attempted to compare different PSD mathematical expressions for soils (e.g., Bayat et al., 2015; Buchan et al., 1993; Hwang et al., 2002; Hwang, 2004; Bah et al., 2009). However, these studies generally compared only a limited number of PSD models (Bagarello et al., 2009; Buchan et al., 1993; Hwang, 2004; Vipulanandan and Ozgurel, 2009), invoked only few statistical criteria for the comparisons (Bagarello et al., 2009; Bayat et al., 2015; Buchan et al., 1993; Hwang, 2004; Vipulanandan and Ozgurel, 2009) and/or applied the analyses to a relatively narrow range of soil textural classes (Buchan et al., 1993; Vipulanandan and Ozgurel, 2009; Zhao et al., 2011). Since the performance of a PSD model depends on the type and range of soil textures involved (e.g., Bagarello et al., 2009; Buchan, 1989; Fredlund et al., 2000; Hwang, 2004; Hwang et al., 2002; Zhao et al., 2011), conclusions obtained with such studies may not necessarily be extended or generalized to soil textures other than those used in the comparisons. Additionally, PSD models have often been evaluated in terms of their general performance for describing the entire PSD curve, but frequently not for predicting specific (and practically-important) PSD points or parameters. A given model may well be accurate globally in terms of generating the entire PSD curve, while failing locally to predict specific points or selected parameters of the curve.

Soil PSD data are commonly used to derive pedotransfer functions (PTFs) for estimating soil hydraulic and other properties that are more difficult to measure directly. Traditionally, 
soil SSC percentages have been used as input data for the PTFs (e.g., Carsel and Parrish, 1988; Chapuis, 2012; Jabro, 1992; Patil and Singh, 2016; Saxton et al., 1986). While attempts have been made to test parameters other than SSC to represent soil particle size information in PTFs, it is not obvious which PSD models are most suitable for this purpose. Also, there is often no clear physical basis of the parameters in some of PSD models. Many PSD model parameters frequently are purely empirical without any physical significance. For these reasons, studies are still needed to obtain optimal correlations of PSD parameters with soil properties in terms of underlying physical concepts.

The objectives of this study were to (1) evaluate the performance of 19 models for describing PSD data of selected soils in northwestern Iran using a broad database in terms of soil textures, (2) provide a functional evaluation of the models to predict selected practically-important PSD points or parameters using different efficiency criteria, (3) compare results obtained with the general and functional evaluations, and (4) correlate physically based PSD model parameters with selected soil physical properties to examine their suitability to serve as input for pedotransfer functions.

\section{MATERIALS AND METHODS Soil datasets}

Twenty four locations neighboring the western edge of threatened hypersaline Lake Urmia in northwestern Iran were sampled for this study. The locations were selected such that soils with a wide range of soil textures were included in the database. Figure 1 shows the textural distributions of the samples. The study area was located between geographical coordinates of $45^{\circ} 05^{\prime}$ and $45^{\circ} 08^{\prime} \mathrm{E}$, and $37^{\circ} 32^{\prime}$ and $37^{\circ} 38^{\prime} \mathrm{N}$, at 1290 to $1350 \mathrm{~m}$ above mean sea level, and with mean annual precipitation and temperature of approximately $300 \mathrm{~mm}$ and $11.8^{\circ} \mathrm{C}$, respectively, with xeric soil moisture and mesic soil temperature regimes (Banaei, 1998).

Three replicate surface $(0-30 \mathrm{~cm}$ depth) soil samples were collected at each site. After clay deflocculation using sodiumhexametaphosphate and mechanical agitation, soil PSD curves were determined using a combination of hydrometer (Gee and Or, 2002) and mechanical sieving methods. Fine particle fractions $(<0.15 \mathrm{~mm})$ were determined by sedimentation, whereas the coarser fractions $(\geq 0.15 \mathrm{~mm}$ ) were obtained by sieving. The sieve analysis involved nested columns of sieves $(2,1,0.5$, 0.25 and $0.15 \mathrm{~mm})$, which were shaken with a mechanical shaker. Twelve data points were obtained from the hydrometer analysis by recording the soil suspension density at times of 30 , 40 and $60 \mathrm{~s}$, and at 3, 10, 15, 30, 60, 90, 120, 240 and 1440 $\mathrm{min}$. A total of 16 hydrometer particle size limits hence were obtained for each soil sample.

Once the cumulative PSD curves (i.e., $F(d)$ as a function of the particle diameter, $d$ ) were obtained, the geometric mean $d_{g}$ and geometric standard deviation $\sigma_{g}$ of the soil particle diameters were determined using methods proposed by Shirazi and Boersma (1984). We also determined the mean weight diameter (MWD) of soil aggregates after dry sieving.

Soil particle data larger than $53 \mu \mathrm{m}$ as measured with the sieve method were used to obtain direct estimates of the "measured" sand content. These measured values were then used to test the accuracy of the PSD models to predict the sand content from the complete grain size distribution using complete $F(d \geq$ $53 \mu \mathrm{m})$. We further compared the SSC contents obtained with the hydrometer data at sedimentation times of $40 \mathrm{~s}$ and $7 \mathrm{hr}$, further referred to as the "nominal" SSC contents, with PSD model-predicted $F(d)$ values corresponding to diameters $(d)$ of $2-0.05,0.05-0.002$, and $<0.002 \mathrm{~mm}$ for sand, silt, and clay, respectively.

We also estimated "measured" particle-size diameters corresponding to 10,30 , and $60 \%$ of the cumulative PSD curve (i.e. $D_{10}, D_{30}$, and $D_{60}$, respectively) by linear interpolation from the nearest lower and higher measured data points (a common procedure to determine $D_{10}, D_{30}$, and $D_{60}$ values). These measured values were compared with $D_{10}, D_{30}$, and $D_{60}$ values "predicted" with the complete $F(d)$ models.

Several other soil physical parameters were obtained at the study site. The field-saturated soil hydraulic conductivity $\left(K_{f s}\right)$ was measured using constant head single-ring methods (Razzaghi et al., 2016; Reynolds, 2008), while the soil bulk density $\left(\rho_{b}\right)$ was determined using core sampling (Blake and Hartge, 1986). To determine total porosity $(\Phi)$, the soil cores were slowly saturated by soaking them from below to a water level just below the top of the core. This procedure was carried out over a period of 2 days to obtain as complete saturation as possible by minimizing entrapped and dissolved air in the cores. Soil water contents as determined subsequently by ovendrying the saturated samples at $105^{\circ} \mathrm{C}$ for $24 \mathrm{hr}$ were regarded to be equivalent to porosity, $\Phi$ (Khodaverdiloo et al., 2011).

\section{Particle-size distribution models}

In this study we compared the performance of 19 different mathematical models for $F(d)$ in describing observed cumulative PSD data of the sampled Urmia soils. The models are listed in Table 1. The references cited in the second column of Table 1 provide details of the corresponding model shown in the third column.

\section{Fitting procedure}

An iterative nonlinear optimization procedure was used to fit the parametric functions $F(d)$ in Table 1 to the observed cumulative PSD data. The optimization procedure produced values of the unknown parameters that provided the best fit with the data (Bagarello et al., 2009; Bah et al., 2009; Hwang et al., 2002). Optimized values of the model parameters were determined by minimizing the following objective function:

$$
S S E=\sum_{i=1}^{n}\left(O_{i}-P_{i}\right)^{2}
$$

where $S S E$ represents the sum of squared errors between the measured $\left(O_{i}\right)$ and predicted $\left(P_{i}\right)$ cumulative PSD fractions, and $n$ the number of particle size data points.

The optimization procedure was implemented using the least-square curve fitting toolbox in the MATLAB R2011a environment (The MathWorks Inc., Natick, MA). The final fitted parameter values in each case were tested by using at least three different initial parameter estimates as done by Hwang et al. (2002) and Bah et al. (2009), among others. The optimization process in most or all cases converged to the same final values, thus avoiding the problem of selecting local minima.

\section{Criteria for model comparison}

After optimization of the model parameters, values of the cumulative PSD fractions as calculated with the $F(d)$ models were compared with their corresponding observed values to test how well the calibrated models fitted the observed PSD data. 
Table 1. Particle-size distribution models, $F(d)$, tested in this study.

\begin{tabular}{|c|c|c|c|}
\hline Model & Reference & Equation $^{\#}$ & Parameters \\
\hline $\mathrm{AD}$ & Andersson (1990) & $F(d)=f_{o}+b \arctan \left(c \log \frac{d}{d_{o}}\right)$ & $f_{o}, b, c, d_{o}$ \\
\hline G (Gompertz) & Nemes et al. (1999) & $\mathrm{F}(\mathrm{d})=\alpha+\gamma \exp \{-\exp [-\beta(d-\mu)]\}$ & $\alpha, \beta, \mu, \gamma$ \\
\hline $\begin{array}{l}\text { Fred-3p (Fredlund with } 3 \\
\text { parameters) }\end{array}$ & Fredlund et al. (2000) & $F(d)=\frac{1}{\left\{\ln \left[\exp (1)+\left(\frac{\alpha}{d}\right)^{n}\right]\right\}^{m}}\left\{1-\left[\frac{\ln \left(1+\frac{0.001}{d}\right)}{\ln \left(1+\frac{0.001}{d_{m}}\right)}\right]^{7}\right\}$ & $\begin{array}{l}a, n, m \\
d_{m}=0.0001\end{array}$ \\
\hline $\begin{array}{l}\text { Fred-4p (Fredlund with } 4 \\
\text { parameters) }\end{array}$ & Fredlund et al. (2000) & $F(d)=\frac{1}{\left\{\ln \left[\exp (1)+\left(\frac{\alpha}{d}\right)^{n}\right]\right\}^{m}}\left\{1-\left[\frac{\ln \left(1+\frac{d_{f}}{d}\right)}{\ln \left(1+\frac{d_{f}}{d_{m}}\right)}\right]^{7}\right\}$ & $\begin{array}{l}n, m, d_{f}, \alpha \\
d_{m}=0.0001\end{array}$ \\
\hline $\begin{array}{l}\text { ORL (Offset-Renormalized } \\
\text { Lognormal) }\end{array}$ & Buchan et al. (1993) & $\begin{array}{l}G(X)=(1-\varepsilon) F(X)+\varepsilon \\
F(X) \text { defined by SLN model }\end{array}$ & $\mu, \sigma, \varepsilon$ \\
\hline $\begin{array}{l}\text { ORN (Offset- } \\
\text { Nonrenormalized Lognor- } \\
\text { mal) }\end{array}$ & Buchan et al. (1993) & $\begin{array}{l}\mathrm{G}(\mathrm{X})=\mathrm{F}(\mathrm{X})+c \\
\mathrm{~F}(\mathrm{X}) \text { defined by SLN model }\end{array}$ & $\mu, \sigma, c$ \\
\hline $\mathrm{SH}-\mathrm{C}$ & $\begin{array}{l}\text { Shiozawa and Campbell } \\
\text { (1991) }\end{array}$ & $\begin{array}{l}G(X)=\varepsilon F_{1}(X)+(1-\varepsilon) F_{2}(X) \\
F(X) \text { defined by SLN model }\end{array}$ & $\mu, \sigma, \varepsilon$ \\
\hline $\begin{array}{l}\text { MLG (Modified Logistic } \\
\text { Growth function) }\end{array}$ & Liu et al. (2004) & $F(d)=\frac{1}{\left[1+a \exp \left(-b d^{c}\right)\right]}$ & $a, b, c$ \\
\hline Wei (Weibull) & Assouline et al. (1998) & $\begin{array}{l}F(d)=c+(1-c)\left\{1-\exp \left(-a D^{b}\right)\right\} \\
D=\frac{\left(d-d_{\min }\right)}{\left(d_{\max }-d_{\min }\right)}\end{array}$ & $c, a, b$ \\
\hline SLN (Simple Lognormal) & Buchan (1989) & $\begin{array}{l}F(X)=\frac{1}{2}\left(1-\operatorname{erf}\left(\frac{X-\mu}{\sigma \sqrt{2}}\right) \quad X \leq \mu\right. \\
X=\ln (d)\end{array}$ & $\mu, \sigma$ \\
\hline Norm (Normal) & Buchan et al. (1993) & $\begin{array}{l}F(X)=\frac{1}{2}\left(1+\operatorname{erf}\left(\frac{X-\mu}{\sigma \sqrt{2}}\right) X>\mu\right. \\
X=\ln (d)\end{array}$ & $\mu, \sigma$ \\
\hline VG & $\begin{array}{l}\text { Haverkamp and Par- } \\
\text { lange (1986) }\end{array}$ & $F(d)=\left[1+\left(\left(\frac{d_{g}}{d}\right)^{n}\right)\right]^{-m}$ & $\begin{array}{l}d_{g}, n \\
(m=1-1 / n)\end{array}$ \\
\hline $\begin{array}{l}\text { BEST (Beerkan Estimation } \\
\text { of Soil Transfer) }\end{array}$ & Lassabatère et al. (2006) & $F(d)=\left[1+\left(\frac{d_{g}}{d}\right)^{N}\right]^{-M}$ & $\begin{array}{l}d_{g}, N, M \\
M=1-2 / N \\
\end{array}$ \\
\hline $\operatorname{Fr}(B)$ (Fractal) & Bird et al. (2000) & $F(d)=c d^{(3-D m)}$ & $c, D m$ \\
\hline Fr (T-W) (Fractal) & $\begin{array}{l}\text { Tyler and Wheatcraft } \\
\text { (1992) }\end{array}$ & $F(d)=\left(\frac{d}{1.5}\right)^{(3-D m)}$ & $D m$ \\
\hline L-P (Log-power) & Kolev et al. (1996) & $F(d)=A \exp (B \log d)$ & $A, B$ \\
\hline Exp (Exponential) & Gimenez et al. (2001) & $F(d)=c d^{-\beta}$ & $c, \beta$ \\
\hline Log (Logarithmic) & Zhuang et al. (2001) & $F(d)=a \ln d+b$ & $a, b$ \\
\hline $\mathrm{J}$ & Jaky (1944) & $F(d)=\exp \left\{\frac{1}{\mathrm{p}^{2}}\left[\ln \left(\frac{\mathrm{d}}{\mathrm{d}_{0}}\right)\right]^{2}\right\}$ & $\begin{array}{l}p>1 \\
\left(d_{0}=2 \mathrm{~mm}\right)\end{array}$ \\
\hline
\end{tabular}

${ }^{\#} d$ : particle diameter in $\mathrm{mm} ; F(d)$ : cumulative fraction with a diameter smaller than $d$; erf: error function

The accuracy of the models was evaluated using the NashSutcliffe Efficiency (NSE), the root mean square error (RMSE), the coefficient of determination $\left(R^{2}\right)$, the index of agreement $(\delta)$, the relative error $(E r)$, Akaike's information criterion (AIC), the standard deviation of error (STDEV), the maximum error $\left(M A X_{e}\right)$, the mean absolute error percentage $(M A E P)$, the maximum absolute error percentage $\left(M A X_{a e p}\right)$, and the geomet- ric mean of error ratio (GMER). Mathematical representations of these criteria are given in Table 2.

We used the various statistical measures in Table 2 to evaluate different aspects of the optimizations. This was done since some of the criteria emphasize the optimizations more from a perspective of variances, while other statistics capture the bias better. For example, RMSE is an index of the absolute error. 
Table 2. Efficiency criteria used to evaluate the accuracy of the PSD models.

\begin{tabular}{|l|l|}
\hline Criteria & Model Equation ${ }^{\#}$ \\
\hline RMSE & $R M S E=\left\{\frac{\sum_{i=1}^{n}\left(O_{i}-\bar{O}\right)\left(P_{i}-\bar{P}\right)}{\sqrt{\left.\frac{1}{n} \sum_{i=1}^{n}\left(O_{i}-\bar{O}\right)\right]^{2}} \sqrt{\left[\sum_{i=1}^{n}\left(P_{i}-\bar{P}\right)\right]^{2}}}\right\}^{2}$ \\
\hline AIC & $A I C=N \ln \left(\frac{S S E}{n}\right)+2(P+1)+\frac{2(P+1)(P+2)}{n-P-2}$ \\
\hline Er & $E r=\sqrt{\frac{\sum_{i=1}^{n}\left(P_{i}-O_{i}\right)^{2}}{\sum_{i=1}^{n}\left(O_{i}\right)^{2}}}$ \\
\hline NSE & $N S E=1-\frac{\sum_{i=1}^{n}\left(P_{i-} O_{i}\right)^{2}}{\left(O_{i}-\bar{O}\right)^{2}}$ \\
\hline$\delta$ & $\delta=1-\left\{\frac{\sum_{i=1}^{n}\left(O_{i}-P_{i}\right)^{2}}{\sum_{i=1}^{n}\left(\left|P_{i}-\bar{O}\right|+\left|O_{i}-\bar{O}\right|\right)^{2}}\right\}$ \\
\hline GMER & $G M E R=\exp \left(\frac{1}{n} \sum_{\left.\ln \left(\frac{P_{i}}{O_{i}}\right)\right)}\right.$ \\
\hline MADEV & $S T D E V=S T D E V\left(P_{i}-O_{i}\right)$ \\
\hline MAX $_{\mathrm{e}}$ & $M A X_{e}=\operatorname{MAX}\left|P_{i}-O_{\mathrm{i}}\right|$ \\
\hline & $M A E P=\left(\sum_{\mathrm{i}=1}^{\mathrm{n}}\left|\frac{P_{i}-O_{i}}{P_{i}}\right|\right) / n \times 100$ \\
\hline
\end{tabular}

${ }^{\#} n$ refers to the number of calculated $\left(P_{i}\right)$ and measured $\left(O_{i}\right)$ values of the cumulative PSD curve; over-lined symbols represent mean values; $S S E$ is the sum of squared errors; $P$ is the number of model parameters.

However, models with more fitting parameters will almost always result in a better overall fit. The $A I C$ is for this reason often used to compare models with different numbers of fitting parameters. In this study we used the corrected $A I C$ as suggested by Bolster and Hornberger (2007).

NSE values were selected to indicate whether or not the observed mean is as good a predictor as the model. On the other hand, $R^{2}$ is an indicator of the extent to which the model explains the total variance of the observed data. To overcome some of the limitations of $R^{2}$, Willmott (1981) proposed the index of agreement, $\delta$, to better reflect the degree at which observations are estimated accurately by the predictions. However, relatively high values (more than 0.65 ) of $\delta$ may be obtained even for poor model fits, and $\delta$ hence is not overly sensitive to systematic over- or under-predictions. We used GMER to test the possible under- or over-estimations in the model predictions, while $M A X_{e}$ is used to show the outliers. Since errors within the lower range of the model output may be masked by relatively high errors in the higher range of the output, $M A E P$ and $M A X_{\text {aep }}$ have been used to compare the errors and outliers, respectively, of the models as percentages of the observed values. For a perfect prediction $R M S E, S D$, $M A X_{e}, M A E P, M A X_{a e p}$ and $E r$ equal zero and NSE, $\delta, R^{2}$, and GMER equal 1. Models with lower $A I C$ values are considered to be the more likely to be accurate.
Since most or all statistical criteria evaluate only some aspect of the correspondence between measured and calculated values, we suggest that a complete assessment of model performance should include a combination of criteria. We evaluated for this reason initially all of the criteria in Table 2 for the $F(d)$ models. The criteria subsequently were classified into groups using a hierarchical cluster analysis (HCA) based on the levels of similarity among their standardized values. Finally, a subset of the criteria was selected among the distinct groups to evaluate and compare the performance of the models. The selected criteria were then used to classify the models into groups using HCA. The cluster analysis was conducted using the Minitab 16 software.

Once the different $F(d)$ models and their optimized parameters were determined, measured $K_{f s}, \log K_{f s}, \mathrm{MWD}$, and $\Phi$ values were correlated with either the conventional PSD parameters (i.e., sand/silt/clay percentages), geometric representations of the PSDs $\left(d_{g}\right.$ and $\left.\sigma_{g}\right)$, selected PSD mechanical parameters (notably $D_{50}$ and $D_{60}$ ), and the optimized parameters of the most accurate $F(d)$ models. This is to find the best representation(s) of the soil PSDs to predict relevant soil physical quality indices, and to interpret correlations of soil PSD data with field properties. For the functional evaluation of the models against the field data we used selected practically-important PSD parameters such as sand, silt and clay percentages, $d_{g}$ and $\sigma_{g}$, and $D_{30}, D_{50}$ and $D_{60}$ as calculated with the $F(d)$ models.

The accuracy of the models in terms of predicting $K_{\mathrm{fs}}$, $\log K_{\mathrm{fs}}$, MWD, and $\Phi$ values was assessed using a weighted version of $R^{2}$ (i.e., $w R^{2}$ ) following Krause et al. (2005):

$w R^{2}=\left\{\begin{array}{l}|b| \cdot R^{2} \text { for } b \leq 1 \\ |b|^{-1} \cdot R^{2} \text { for } b>1\end{array}\right.$

where the weighting factor, $b$, and $R^{2}$ are, respectively, the gradient and the coefficient of determination of the regression of predicted versus observed values of a given parameter. The advantage of Eq. (2), as opposed to $R^{2}$, is that only a single but more effective criterion is used for the comparisons. Models which systematically over- or under-predict observed data all the time will still result in $R^{2}$ values close to 1.0 , even if all predictions are incorrect. This problem can be avoided by using additional information about the regression. Such information is provided by the gradient $b$ and the intercept $a$ of the regression on which $R^{2}$ is based. For good agreement the intercept $a$ should be close to zero (which means that an observed value at or near zero would also result in a prediction at or near zero), while the gradient $b$ should be close to 1.0 . By using $w R^{2}$, systematic under- or over-predictions are quantified, together with the regression as such, thus leading to a more comprehensive reflection of model results (Krause et al., 2005).

\section{RESULTS AND DISCUSSION}

Statistical descriptions of selected physical and chemical properties of the soils used in this study are presented in Table 3. The data show that the soils differed widely in their PSD. For example, $C V$ values of clay and silt contents were 48 and $55 \%$, respectively, while the soil textural classes ranged from sandy loam to clay as shown in Fig. 1. On the other hand, $\mathrm{pH}$ values were within a relatively narrow range among the soils studied. The calcium carbonate equivalent (CCE) of all soils was above $7.3 \%$ and the $\mathrm{pH}$ was equal to 7.5 or more, which indicates that the soils were calcareous and alkaline. The organic matter $(\mathrm{OM})$ content varied widely among the soils $(C V=53 \%)$. Most 
Table 3. Maximum (Max), Minimum (Min), Mean and Standard Deviation (STDEV) of selected physico-chemical properties of the soil samples.

\begin{tabular}{|l|c|c|c|c|c|c|}
\hline Soil property & Maximum & Minimum & Mean & STDEV & Range & CV \\
\hline Clay $(\%)$ & 52 & 8 & 27 & 13 & 45 & 48 \\
\hline Silt $(\%)$ & 60 & 30 & 44 & 8 & 30 & 18 \\
\hline Sand $(\%)$ & 59 & 8 & 29 & 16 & 51 & 55 \\
\hline $\mathrm{pH}$ & 8.5 & 7.5 & 8.2 & 0.5 & 1 & 5.5 \\
\hline $\mathrm{CCE}(\%)$ & 33.5 & 17.3 & 23.3 & 7.2 & 16 & 31 \\
\hline OM $(\%)$ & 5.98 & 0.89 & 2.94 & 1.55 & 5 & 53 \\
\hline$\rho_{b}\left(\mathrm{~g} \mathrm{~cm}^{-3}\right)$ & 1.46 & 0.94 & 1.22 & 0.11 & 0.52 & 9.31 \\
\hline EC $\left(\mathrm{d} \mathrm{m}^{-1}\right)$ & 85.4 & 0.8 & 14.4 & 22.9 & 85 & 159 \\
\hline ESP $\left(\mathrm{cmol}_{+} \mathrm{kg}^{-1}\right)$ & 71.0 & 4.0 & 25.5 & 18.0 & 67 & 71 \\
\hline$K_{f s}\left(\mathrm{~cm} \mathrm{day}^{-1}\right)$ & 970.6 & 0.34 & 201.2 & 260.4 & 970 & 129.4 \\
\hline
\end{tabular}

EC, Electrical conductivity; ESP, Exchangeable sodium percentage; CCE, Calcium carbonate equivalent; OM, Organic matter content; $\rho_{b}$, Bulk density, $K_{f s}$, Saturated hydraulic conductivity.

of the soils were either saline/sodic $(n=14)$ or non-saline/nonsodic $(n=8)$.

\section{Comparison of the fitting ability of the PSD models}

Box plots of the statistical criteria of the applied PSD models for the 24 soils are given in Fig. 2. Results indicate that the values of $R^{2}, \delta, N S E$, and GMER differed in a narrow range among the models $(C V<6.2 \%)$. This shows that these criteria are not very effective in representing differences in the accuracy of the models. By comparison, $A I C$ varied moderately $(C V=$ $18.7 \%$ ), whereas $R M S E, M A X_{e}, M A E P, S T D E V$, and $M A X_{a e p}$ varied more widely $(C V>50 \%)$ among the models.

Mean values of $R^{2}$ ranged from 0.820 to 0.994 (Fig. 2). The Wie and Fred-4p models for $F(d)$ showed the highest $R^{2}$ values, ONL, Fred-3p and MLG models showed similar intermediate performance, while the $\operatorname{Fr}(\mathrm{T}-\mathrm{W}), \operatorname{Fr}(\mathrm{B}), \mathrm{Exp}$, and L-E models had the lowest $R^{2}$ values. The favorable fitting capability of Wie and Fred- $4 p$ reflects their flexibility in terms of describing a wide range of PSD shapes (Bayat et al., 2015). The Wei model also has a physical basis and no overlap in the effects of its parameters on the shape and position of the PSD curve. The Fred-4 $p$ model performed slightly better than the Fred-3p model. This indicates that Fred-3p is probably accurate enough for most soils, with the advantage of having one parameter less (Fredlund et al., 2000). These results are consistent with those by Bayat et al. (2015) who found no difference between the Fred-4p and Fred-3p models in terms of $R^{2}$ and $R M S E$ when applied to the UNSODA database with a broad range of soil textural classes. However, they suggested using the Fred-3p model according to the $A I C$ criterion. The favorable performance of Fred- $4 p$ in describing PSD data was reported also by Hwang et al. (2002) for soils covering a wide range of textures.

Of the three models assuming lognormal curves containing three parameters (i.e., ORL, ONL and SH-C), the $R^{2}$ values were higher for ONL as compared to the ORL and SH-C models. These results agree with those by Hwang et al., (2002), but differ from findings by Buchan et al. (1993) who, for a limited number of soils, found higher average $R^{2}$ values for the SH-C model than the two other models. However, we note that the $C V$ of the $R^{2}$ values in our study was only about $6.2 \%$ among the studied models. This shows that the models are difficult to rank conclusively in terms of their $R^{2}$ values. Similarly, the low values of the coefficient of variation of $\delta, N S E$, and GMER $(<4.3 \%)$ makes it difficult to properly rank those models.

$R M S E$ values of the models ranged from a low of 0.019 for AD to a high of 0.106 for $\operatorname{Fr}(\mathrm{T}-\mathrm{W})$. Fr (T-W) is a single powerlow exponent model which could not properly characterize the
PSD across the whole range of measured data points. For this reason Bitteli et al. (1999) proposed the use of three separate power laws for the clay, silt and sand particle sizes.

The G, Norm, J, Exp, Log, L-E, Fr(B), and Fr(T-W) models performed the poorest as reflected by their high mean $A I C$ values, whereas the other models performed well with very similar low mean $A I C$ values $(A I C<-109)$, as can be seen in Figure 2. In terms of their $A I C$, the Fred-3p, MLG, Wei and Fred-4p models ranked first to fourth. This result differs from that of Shangguan et al. (2014), who found that AD and Wei had the lowest mean $A I C$ values and hence were considered the best PSD models among eleven models that they compared. Considering the average $A I C$ values of all of the soils they studied, Botula et al. (2013) suggested that the number of fitting parameters does not always explain the differences in the quality of the fittings. They found lower $A I C$ values for Fred-4p relative to the models having three, two and one parameters. Bayat et al. (2015) similarly suggested that an increase in the number of fitting parameters in the PSD models does not necessarily lead to better performance. The Gompertz model with four parameters showed the poorest performance in their study. Even though the $A I C$ has a penalty on the number of parameters, the Wei, Fred-3p, MLG models with three parameters were still among the best PSD models in our study.

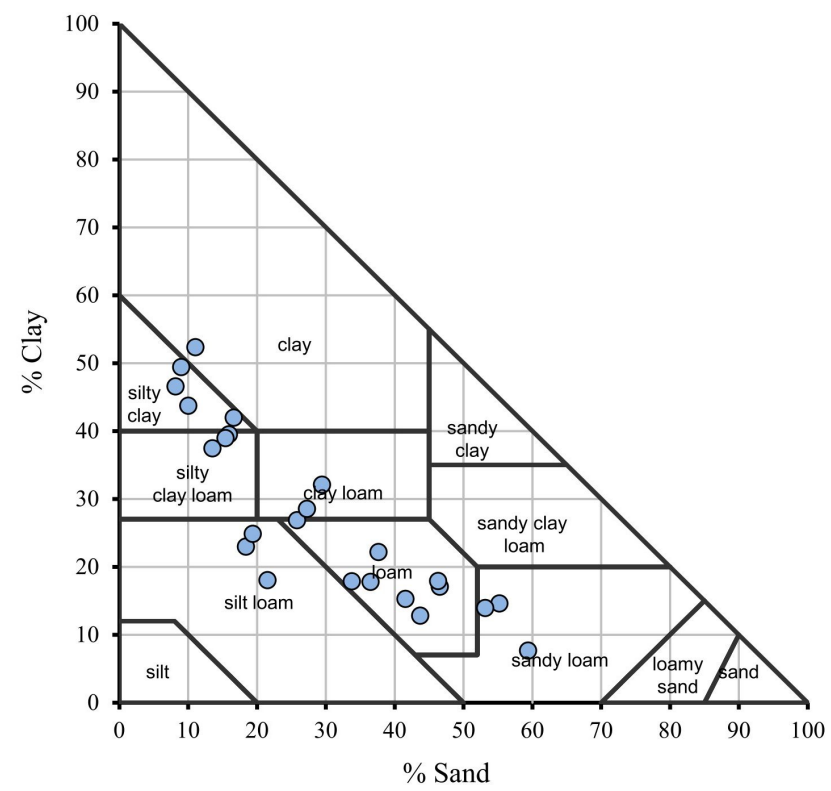

Fig. 1. Textural distribution of the 24 soil samples. 

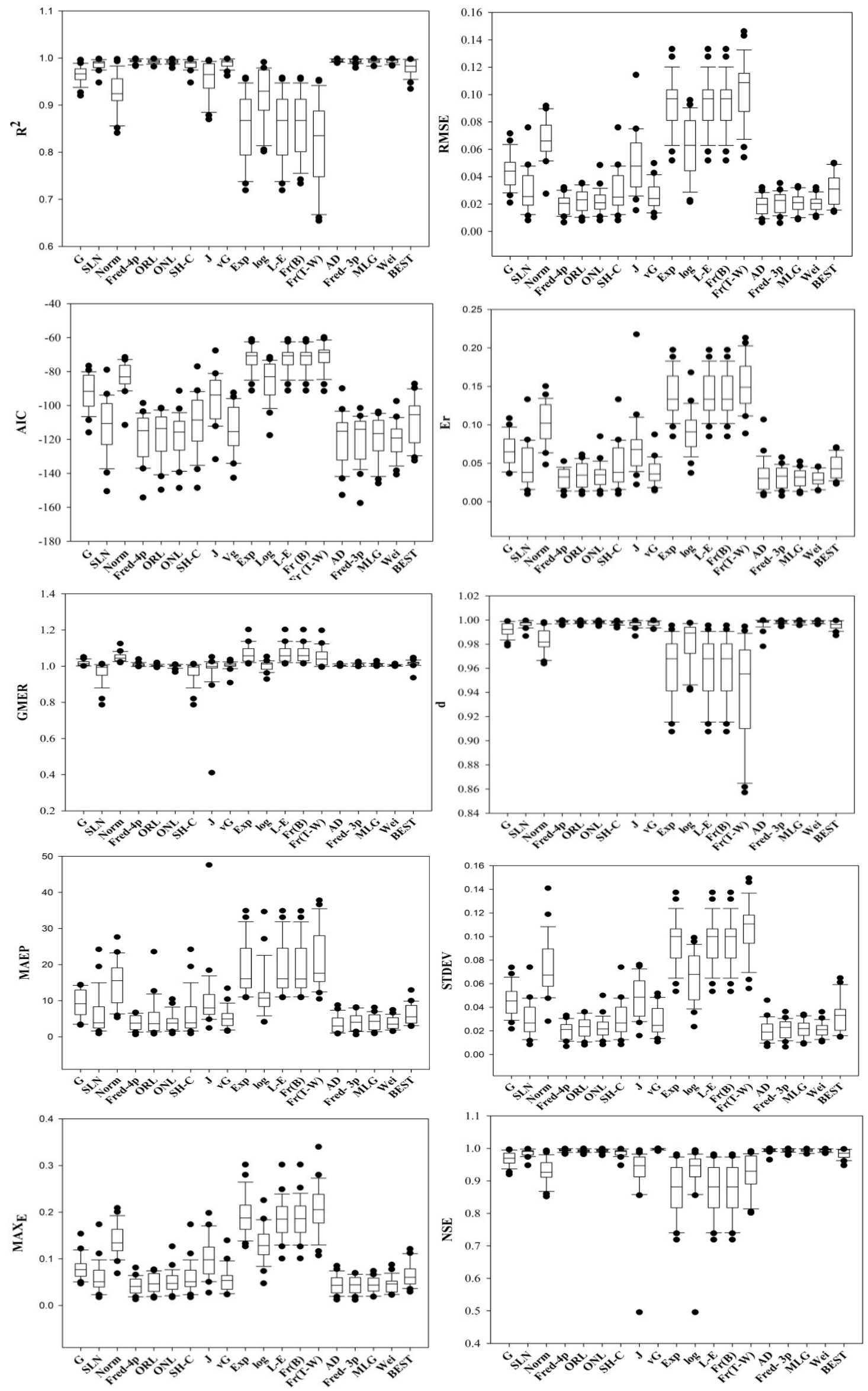

Fig. 2. Box plots of the statistical criteria used to describe the accuracy of 19 models in fitting the cumulative particle-size distribution data of 24 soil samples. The box plots show medians, interquartile ranges, and outliers. The full names and other information about the models (horizontal axes) are given in Table 1. The statistical criteria (vertical axes) are listed in Table 2. 
Comparison of alternative soil particle-size distribution models and their correlation with soil physical attributes

Table 4. Rankings of the six most accurate PSD models in terms of various statistical criteria.

\begin{tabular}{|c|c|c|c|c|c|c|c|c|c|c|c|}
\hline 总 & $\mathrm{R}^{2}$ & AIC & RMSE & Er & d & $\mathrm{MAX}_{\text {aep }}$ & NSE & STDEV & GMER & $\mathrm{MAX}_{\mathrm{e}}$ & MAEP \\
\hline 1 & $\mathrm{AD}$ & Wei & $\mathrm{AD}$ & Fred-4p & Fred-4p & Fred- $4 p$ & VG & Fred-4p & ONL & Fred-4p & $\mathrm{AD}$ \\
\hline 2 & Wei & Fred-3p & Fred-4p & MLG & Wei & Wei & Fred-4p & $\mathrm{AD}$ & ORL & Fred-3p & Wei \\
\hline 3 & Fred-4p & $\mathrm{AD}$ & Wei & Fred-3p & Fred-3p & MLG & Wei & Wei & $\mathrm{AD}$ & MLG & Fred-4p \\
\hline 4 & Fred-3p & MLG & Fred-3p & $\mathrm{AD}$ & MLG & Fred-3p & $\mathrm{AD}$ & Fred-3p & Wei & $\mathrm{AD}$ & ONL \\
\hline 5 & MLG & Fred-4p & MLG & ONL & ONL & $\mathrm{AD}$ & Fred-3p & MLG & VG & Wei & Fred-3P \\
\hline 6 & ONL & ORL & ONL & ORL & ORL & ONL & MLG & ONL & Log & ORL & MLG \\
\hline
\end{tabular}

Regarding the relative error (Er), Bagarello et al. (2009) considered that $E r$ values of less than 5\% indicate a satisfactory fitting performance of the PSD function. In our study Fred-4p, MLG, Fred-3p, ONL, AD, ORL, vG, BEST, Wei, SH-C, and SLN all had $E r$ values less than 5\%, which would suggest that these models all performed well. Other models had $\mathrm{Er}$ values larger than 5\%. The Er values of Exp, L-E, $\operatorname{Fr}(\mathrm{B})$ and $\operatorname{Fr}(\mathrm{T}-\mathrm{W})$ in particular were very high $(\geq 13 \%)$.

The mean value of $M A X_{e}$ among the models differed widely from 0.042 to 0.207 , indicating outlier error values of 4.2 to 20.7 percent in the cumulative fractions. The Fred-4p, Fred-3p, MLG, and Wei models showed the lowest (and very similar) outlier errors $\left(M A X_{e}=0.042\right.$ to 0.046$)$. On the other hand, the $\operatorname{Fr}(\mathrm{T}-\mathrm{W}), \operatorname{Fr}(\mathrm{B}), \mathrm{L}-\mathrm{E}$, and Exp models had the highest outliers $\left(M A X_{e} \geq 0.136\right)$.

The highest $M A E P$ values were obtained with the Exp, Log, L-E, $\operatorname{Fr}(\mathrm{B}), \operatorname{Fr}(\mathrm{T}-\mathrm{W})$, and Norm models (MAEP values between 12.5 and $21.5 \%$ ). MAEP values of the $\mathrm{G}$ and $\mathrm{J}$ models were moderate (about 10\%) and those of the other models about $6 \%$ or less. The lowest $M A E P$ values were obtained for Fred-4p, Fred-3p, Wei, MLG, and AD; MAEP values of these models were very similar, varying between 3.91 and $4.41 \%$.

The tendency of the models to predict cumulative fractions with outlying errors is most effectively described using $M A X_{a e p}$. This efficiency criterion varied widely among the models from 6.7 to $47.6 \%$ (Fig. 2). The lowest values were obtained for the Fred-4p, Fred-3p, and MLG models, which produced fairly similar values between 6.7 and $8.2 \%$. A relatively large group of models (i.e. G, Wei, BEST, AD, and ONL) had moderate $M A X_{\text {aep }}$ values ranging from 12.9 to $16.5 \%$. MAX aep values of the other models were higher than $23.6 \%$.

The STDEV of the errors of the models ranged from 0.02 to 0.11 (Fig. 2). The models having the highest standard deviations were VG, L-E, $\operatorname{Fr}(B)$, and $\operatorname{Fr}(\mathrm{T}-\mathrm{W})$, whereas Fred-4p, Fred-3p, MLG, and AD models had the lowest variations in the error (i.e. the lowest $S T D E V$ values). These and several other efficiency criteria are partly in agreement with published results. For example, in a study evaluating the accuracy of 11 PSD models for the conversion of Chinese data to the FAO/USDA System, Shangguan et al. (2014) reported much better performance of the AD, Fred-4p, MLG, and Wei models compared to the other models. Botula et al. (2013), Zhao et al., (2011) and Hwang (2004) found the fractal models as well as the Exp and L-E models to be less accurate in their study. Evaluating the performance of 14 PSD models for characterizing the size distribution of sediments of dams in China, Zhao et al. (2011) identified Fred- $4 p$ as the best performing model, while of the 3-parameter formulations the Wei model performed the best. The $\mathrm{J}$ model was found to perform the best among the one-parameter models. Zhao et al. (2011) furthermore found the fractal models, Exp, Log and L-E to be the least accurate. Buchan et al. (1993) reported similar results. However, our study indicated ORL, ONL and SLN to be superior to the J model. Hwang et al. (2002) and Liu et al. (2003) identified Fred- $4 p$ as the best PSD model for a wide range of soil types.

Table 4 shows the ranking of the six most accurate models of our study in terms of the various efficiency criteria we used. The data show that using different criteria will lead to different rankings of the models. For example, if one uses NSE to rank the models, VG would be the most accurate model followed by Fred-4p, Wei, AD, Fred-3p, and MLG. On the other hand, according to the $M A X_{\text {aep }}$ criterion, the Fred-4p model was the most accurate followed by Wei, MLG, Fred-3p, and AD, while RMSE values ranked the models as Wei, Fred-4p, Fred-3p, MLG, and ONL (Table 4). However, we note that the differences in the values of most of the criteria among the most accurate models are generally not very substantial.

Mean absolute error percentages over all soils as obtained with the six most accurate models are plotted against the particle diameter in Fig. 3. The plots indicate that the prediction error of the models depends upon the diameter at which the cumulative PSD fraction is calculated. Much higher error percentages occurred when predicting the cumulative fraction for smaller particles. When evaluating the accuracy of a certain PSD model, an important issue here is that one should consider the range of soil particle sizes for which the model will be used. A model may be accurate enough for predicting the particle diameter at a certain point or within a certain range, or maybe even on average over the entire PSD curve, but not within another range of particular sizes. Applying the model to inappropriate ranges of particle sizes may lead to large errors.

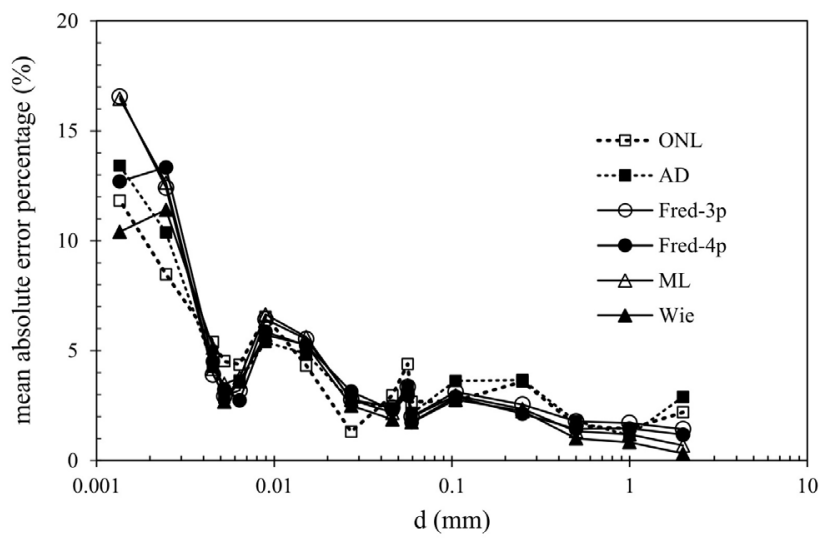

Fig. 3. Mean absolute error percentages of the six most accurate models as a function of soil particle diameter.

\section{Classifying the evaluation criteria and PSD models}

Figure 4 shows results when classifying the evaluation criteria in groups based on the level of similarity among their values. If, in this figure, the similarity of two criteria is high, their correlation will also be high. In general, the efficiency criteria were classified in two major groups, each having six subgroups. 


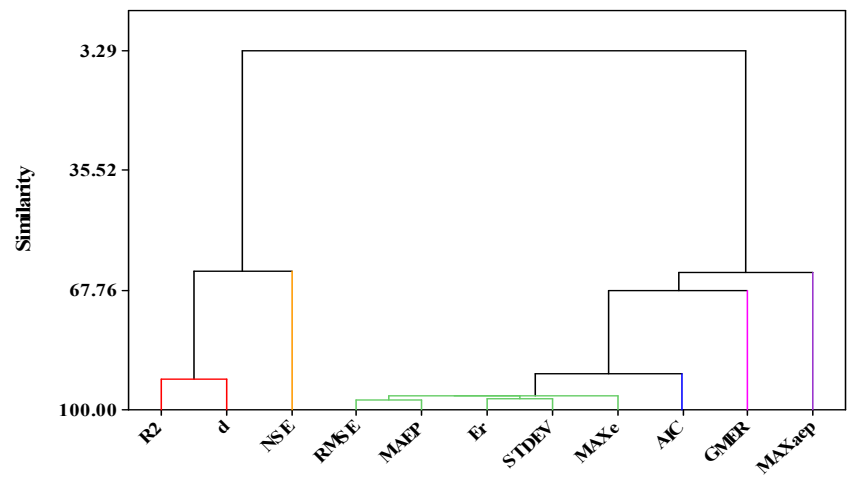

Fig. 4. Hierarchical cluster analysis of the criteria used to evaluate the accuracy of the particle-size distribution models. Information regarding the statistical criteria is given in Table 2 .

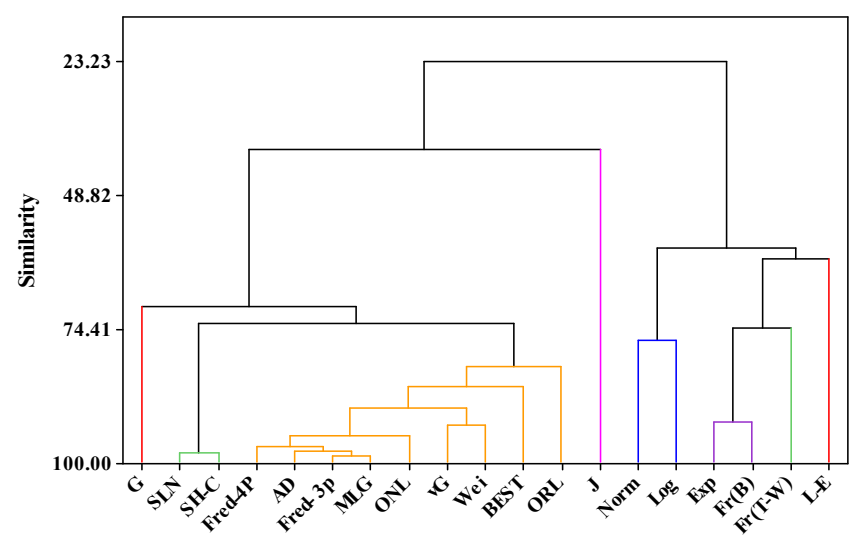

Fig. 5. Hierarchical cluster analysis of the 16 particle-size distribution models in groups based on the level of similarity among their $\mathrm{R}^{2}$, NSE, STDEV, AIC, and GMER values. The full names and other information about the models are given in Table 1; information regarding the statistical criteria is given in Table 2 .

According to these results, six criteria (i.e., $R^{2}, N S E, S T D E V$, $A I C, G M E R$ and $M A X_{\text {aep }}$ ) were selected. The selected criteria were then used to classify the models into groups using a hierarchical cluster analysis based on the level of similarity in their performance (Fig. 5). According to Fig. 5, the PSD models could be classified into eight distinct group/subgroups. The similarity among the Fred-4p, Fred-3p, AD, MLG, ONL, vG, and Wei models was more than $80 \%$. This reflects the similar performance of these seven models in terms of characterizing the PSD of our soils.

\section{Evaluating the soil texture-dependency of the PSD models}

In order to evaluate model performance per textural class, soil samples were divided into two groups based on their textural class (i.e., fine-textured and coarse-textured soils). The fine-textured (FT) soils group $(n=9)$ included 3 silty clay loams, 2 clay loams, one silty clay and one clay, whereas the coarse-textured (CT) soils group $(n=14)$ included 3 silty loams, 8 loams and 3 sandy loams. The minimum, maximum and mean contents of sand were, respectively, 8,29 , and $16 \%$ for the fine-textured and 30, 59, and $38 \%$ for the coarsetextured soils. The values for clay content of the FT and CT soil groups were 28,52 , and $41 \%$ and 8,27 , and $18 \%$, respectively.

Several comparative studies have shown that performance of the PSD models may depend upon soil texture (e.g. Bagarello et al., 2009; Buchan, 1989; Fredlund et al., 2000; Hwang, 2004; Hwang et al., 2002; Zhao et al., 2011). These studies revealed that many or most PSD models performed better for finetextured soils, which would imply that their performance should improve with an increase in the clay content in the soils (e.g. Fredlund et al., 2000; Hwang, 2004; Hwang et al., 2002; Zhao et al., 2011). We compared the efficacy of the best models (Fred-4p, Fred-3p, AD, MLG, ONL, and Wei) in the two soil textural groups using the t-test $(\mathrm{P} \leq 0.05)$ in terms of their mean $R M S E, M A E P$ and $S T D E V$ values over all of the soils involved (Fig. 6). No matter which criterion was used for the comparison, all of the models performed significantly $(\mathrm{P} \leq 0.05)$ better in the fine textured (FT) soils group as compared to the coarse textured (CT) soils (Fig. 6).

The above results partially confirm literature findings. For example, Buchan (1989) pointed out that a log-normal (L-N) model could properly explain all regions of silty clay, silty clay loam, and silt loam soils, whereas sandy clay loams, sandy clays, and much of the clay soils should not be modeled with the L-N model. Liu et al., (2003) similarly found that the Fred$3 p$ and MLG model produced comparable results for silty clay loam and silt loam soils, but yielded worse results for sandy loam soils. In another study, Botula et al., (2013) found that the AD model performed better for relatively fine-textured soils. The generally better performance of the PSD models for finetextured soils may be attributed to the fact that the values of the cumulative fractions for finer particles are lower than those of coarser particles, which may lead to higher prediction errors for coarser particles. This then would produce higher values of the prediction errors for soils containing coarser particles.

We note that the rankings of the models in terms of their $R M S E$ values were not the same for the fine-textured (FT) and coarse-textured (CT) groups. The ranking was Wei $>$ Fred-4p $>$ $\mathrm{AD}>\mathrm{MLG}>$ Fred-3p $>$ ONL for the CT group, and AD $>$ ONL $>$ Fred- $4 p>$ Fred-3p $>$ MLG $>$ Wei for the FT group. However, the ranking for all the soils combined (regardless of their texture) was AD $>$ Fred-4p $>$ Wei $>$ Fred-3p $>$ MLG $>$ ONL.

\section{Functional evaluation of the PSD models}

The data in Table 5 indicate the different performance of the PSD models when estimating different soil PSD indicators or parameters. For example, while the AD and SH-C models predicted the nominal sand fraction (as calculated using hydrometer records at $40 \mathrm{~s}$ ) more accurately, the ONL, Wei and VG models showed better predictions of the silt and clay fractions. The measured sand fraction (particles larger than $53 \mu \mathrm{m}$ as estimated using sieving) was predicted more accurately with the Fred-3p and VG models. Generally, the models were more accurate in predicting the sand and clay fractions than the silt content (Table 5).

While several models were relatively accurate in estimating $d_{g}, \sigma_{g}, D_{50}$, and $D_{60}$ values of the soils, no model was able to predict $D_{30}$ values with acceptable accuracy (Table 5). We note that a common procedure to measure SSC fractions is to use hydrometer readings at specific times of particle settlement in soil suspensions. Resulting size fractions may not necessarily be the same as their actual values (i.e. particles of specific size groups). Also, a common procedure to measure $D_{30}, D_{50}$, and $D_{60}$ is to linearly interpolate between measured cumulative PSD data that are immediately higher and lower than the required point on the PSD curve. Since the PSD curve is generally nonlinear rather than linear, linear interpolation is not always appropriate and hence values derived from the fitted PSD models may be preferred. 

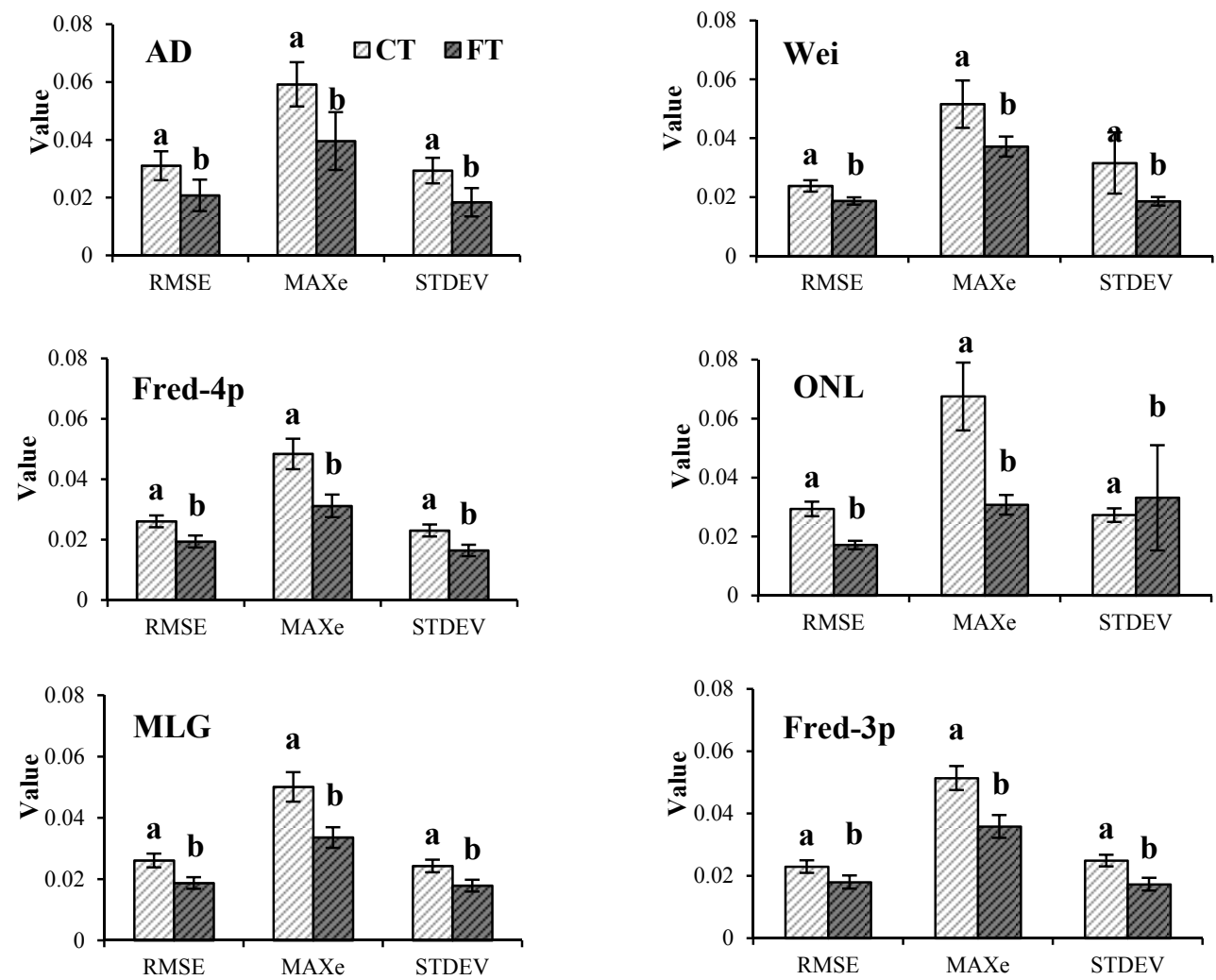

Fig. 6. Comparison of the efficacy of the six most promising particle-size distribution models for the fine-textured (FT) and coarse-textured (CT) soils. The full names and other information about the models are given in Table 1. Information regarding the statistical criteria is given in Table 2. For each criterion the non-similar letters show statistically significant differences $(\mathrm{P} \leq 0.05)$.

Table 5. Weighted $R^{2}$ (equation $2, w R^{2}$ ) values of the studied particle-size distribution models to predict selected parameters of soil PSD.

\begin{tabular}{|l|c|c|c|c|c|c|c|c|c|}
\hline & Sand & Silt & Clay & Sand measured & $d_{g}$ & $\sigma_{g}$ & $D_{60}$ & $D_{50}$ & $D_{30}$ \\
\hline AD & 0.991 & 0.786 & 0.881 & 0.928 & 0.981 & 0.669 & 0.946 & 0.853 & 0.005 \\
\hline BEST & 0.209 & 0.003 & 0.151 & 0.231 & 0.984 & 0.823 & 0.953 & 0.90 & 0.010 \\
\hline Exp & 0.807 & 0.004 & 0.652 & 0.694 & 0.852 & 0.303 & 0.701 & 0.579 & 0.016 \\
\hline Fred-4p & 0.883 & 0.767 & 0.952 & 0.938 & 0.982 & 0.900 & 0.962 & 0.880 & 0.008 \\
\hline Fred-3p & 0.893 & 0.731 & 0.936 & 0.946 & 0.974 & 0.873 & 0.974 & 0.850 & 0.010 \\
\hline Fr(B) & 0.807 & 0.004 & 0.652 & 0.695 & 0.852 & 0.302 & 0.016 & 0.013 & 0.016 \\
\hline Fr(T-W) & 0.761 & 0.00 & 0.615 & 0.647 & 0.819 & 0.113 & 0.641 & 0.496 & 0.018 \\
\hline G & 0.786 & 0.554 & 0.818 & 0.831 & 0.901 & 0.929 & 0.930 & 0.835 & 0.001 \\
\hline J & 0.826 & 0.005 & 0.822 & 0.665 & 0.497 & 0 & 0.529 & 0.532 & 0.010 \\
\hline SLN & 0.962 & 0.590 & 0.876 & 0.833 & 0.827 & 0.877 & 0.770 & 0.768 & 0.006 \\
\hline Log & 0.694 & 0.000 & 0.790 & 0.603 & 0.806 & 0.432 & 0.727 & 0.850 & 0.004 \\
\hline L-E & 0.807 & 0.004 & 0.652 & 0.694 & 0.852 & 0.303 & 0.696 & 0.560 & 0.017 \\
\hline MLG & 0.903 & 0.825 & 0.961 & 0.938 & 0.988 & 0.891 & 0.966 & 0.860 & 0.009 \\
\hline Norm & 0.692 & 0.406 & 0.591 & 0.731 & 0.746 & 0.727 & 0.778 & 0.811 & 0.006 \\
\hline ONL & 0.937 & 0.892 & 0.933 & 0.901 & 0.948 & 0.808 & 0.908 & 0.867 & 0.007 \\
\hline ORL & 0.928 & 0.779 & 0.882 & 0.917 & 0.995 & 0.567 & 0.918 & 0.824 & 0.008 \\
\hline SH-C & 0.963 & 0.592 & 0.867 & 0.834 & 0.827 & 0.877 & 0.770 & 0.769 & 0.006 \\
\hline VG & 0.889 & 0.741 & 0.962 & 0.940 & 0.927 & 0.855 & 0.911 & 0.857 & 0.009 \\
\hline Wei & 0.913 & 0.883 & 0.967 & 0.933 & 0.999 & 0.950 & 0.961 & 0.873 & 0.008 \\
\hline
\end{tabular}

\section{Correlation of PSD parameters with soil physical properties}

We next correlated various representations of the soil PSD (e.g. SSC, $d_{g}$ and $\sigma_{g}, D_{50}$ and $D_{60}$, as well as the model parameters of the most accurate PSD models) with selected soil physical properties. While neither SSC nor $d_{g}, \sigma_{g}, D_{50}$ and $D_{60}$ showed significant statistical correlations with either $K_{f s}$ or $\log K_{f s}$, the fitted parameters of several PSD models correlated significantly with $K_{f s}$ and/or $\log K_{f s}$, as shown in Table 6. Most of the correlations were stronger with $\log K_{f s}$ as compared to $K_{f s}$. Since $K_{f s}$ is known to be one of the most variable soil properties, finding effective inputs to derive PTFs for $K_{f s}$ remains a challenge (e.g. Mbonimpa et al., 2002). Our results suggest that the use of fitting parameters of the PSD models provides an attractive alternative to account for the effects of soil texture on $K_{f s}$.

Correlations between the mean weight diameter (MWD) of soil aggregates with selected PSD model parameters were generally higher for either SSC, $d_{g}$ or $D_{50}$ and $D_{60}$ (Table 6). While, $\Phi$ and $\rho_{b}$ correlated significantly with selected fitting parameters of the PSD models, $\rho_{b}$ showed also significant correlation with many or most geometric $\left(d_{g}\right)$, mechanical $\left(D_{50}\right.$ and $\left.D_{60}\right)$, and agronomic (clay and sand) representations of the PSDs (Table 6), with the exception of the parameters $m$ (Fred-3p) and $c$ (Wei) which showed essentially no correlations. The parameters $d_{f}$ (Fred-4p), $\delta$ (ONL), $b_{0}(\mathrm{AD}), c_{0}$ (AD) correlated only with $\sigma_{g}$, while $m$ (Fred-4p) had a significant positive correlation 
Table 6. Correlations between various PSD model parameters and selected soil physical properties.

\begin{tabular}{|c|c|c|c|c|c|c|c|c|c|c|c|c|}
\hline & $K_{f s}$ & $\log K_{f s}$ & MWD & $\Phi$ & $\rho b$ & $d_{g}$ & $\sigma_{g}$ & $D_{50}$ & $D_{60}$ & Clay & Silt & Sand \\
\hline$\alpha($ Fred-4p) & -0.36 & -0.26 & $-0.67^{* *}$ & -0.27 & $0.52^{*}$ & $0.87^{* *}$ & $0.61^{* *}$ & $0.78^{* * *}$ & $0.87^{* * *}$ & $-0.67^{* * *}$ & $-0.66^{* * *}$ & $0.87^{* * *}$ \\
\hline$d_{f}($ Fred-4p $)$ & 0.18 & 0.23 & -0.14 & -0.03 & -0.06 & 0.21 & $0.50^{*}$ & 0.08 & 0.17 & -0.02 & -0.24 & 0.13 \\
\hline$m$ (Fred-4p) & 0.39 & 0.30 & 0.17 & -0.19 & -0.11 & -0.17 & -0.08 & -0.08 & -0.13 & -0.19 & $0.55^{* *}$ & -0.07 \\
\hline$n($ Fred-4p) & -0.38 & $-0.66^{*}$ & -0.27 & -0.14 & $0.48^{*}$ & $0.54^{* *}$ & 0.05 & $0.64^{* *}$ & $0.64^{* *}$ & $-0.48^{*}$ & -0.36 & $0.58^{* *}$ \\
\hline$c(\mathrm{ONL})$ & $-0.48^{*}$ & $-0.44^{*}$ & $-0.63^{* *}$ & -0.28 & $0.61^{* *}$ & $0.88^{* * *}$ & $0.50^{*}$ & $0.78^{* * *}$ & $0.85^{* * *}$ & $-0.66^{* * *}$ & $-0.68^{* * *}$ & $0.87^{* * *}$ \\
\hline$\mu(\mathrm{ONL})$ & -0.32 & -0.38 & $-0.62^{* *}$ & $-0.43^{*}$ & $0.68^{* *}$ & $0.95^{* * *}$ & $0.46^{*}$ & $0.87^{* * *}$ & $0.91^{* * *}$ & $-0.92^{* * *}$ & $-0.45^{*}$ & $0.97^{* * *}$ \\
\hline$\delta(\mathrm{ONL})$ & -0.01 & -0.28 & -0.16 & -0.07 & -0.19 & -0.11 & $0.67^{* * *}$ & -0.37 & -0.22 & 0.19 & -0.09 & -0.11 \\
\hline$b_{0}(\mathrm{AD})$ & 0.11 & 0.24 & -0.22 & -0.20 & 0.01 & 0.20 & $0.57^{* *}$ & -0.04 & 0.05 & -0.25 & -0.03 & 0.22 \\
\hline$c_{0}(\mathrm{AD})$ & -0.25 & -0.29 & 0.22 & 0.32 & -0.15 & -0.23 & $-0.60^{* *}$ & 0.08 & 0.01 & 0.21 & -0.03 & -0.16 \\
\hline$d_{0}(\mathrm{AD})$ & -0.37 & -0.30 & $-0.62^{* *}$ & -0.27 & $0.57^{* *}$ & $0.96^{* * *}$ & 0.41 & $0.94^{* * *}$ & $0.96^{* * *}$ & $-0.73^{* * *}$ & $-0.68^{* *}$ & $0.91^{* * *}$ \\
\hline$f_{0}(\mathrm{AD})$ & -0.23 & -0.25 & -0.36 & 0.19 & 0.09 & 0.41 & 0.02 & 0.40 & $0.44^{*}$ & -0.05 & $-0.58^{* *}$ & 0.31 \\
\hline$\alpha($ Fred-3p) & -0.40 & -0.38 & $-0.65^{* *}$ & -0.28 & $0.60^{* *}$ & $0.95^{* * *}$ & $0.48^{*}$ & $0.91^{* * *}$ & $0.96^{* * *}$ & $-0.73^{* * *}$ & $-0.68^{* * *}$ & $0.93^{* * *}$ \\
\hline$m$ (Fred-3p) & 0.38 & 0.39 & 0.43 & 0.05 & -0.40 & -0.36 & -0.02 & -0.35 & -0.41 & 0.24 & 0.31 & -0.34 \\
\hline$n$ (Fred-3p) & $-0.42^{*}$ & $-0.65^{* *}$ & -0.38 & -0.17 & $0.49^{*}$ & $0.60^{* *}$ & 0.04 & $0.72^{* * *}$ & $0.70^{* * *}$ & $-0.61^{* *}$ & -0.27 & $0.65^{* *}$ \\
\hline$a$ (MLG) & $0.59^{* *}$ & $0.53^{*}$ & $0.47^{*}$ & 0.40 & $-0.72^{* * *}$ & $-0.59^{* *}$ & -0.25 & $-0.53^{* *}$ & $-0.60^{* *}$ & $0.57^{* *}$ & 0.31 & $-0.62^{* *}$ \\
\hline$b$ (MLG) & $0.46^{*}$ & 0.39 & $0.59^{* *}$ & 0.37 & $-0.62^{* *}$ & $-0.68^{* * *}$ & $-0.64^{* *}$ & $-0.58^{* *}$ & $-0.71^{* * *}$ & $0.63^{* *}$ & $0.46^{*}$ & $-0.75^{* * *}$ \\
\hline$c$ (MLG) & $-0.43^{*}$ & $-0.60^{* *}$ & $-0.52^{*}$ & -0.20 & $0.55^{* *}$ & $0.75^{* * *}$ & 0.33 & $0.77^{* * *}$ & $0.79^{* * *}$ & $-0.71^{* * *}$ & -0.39 & $0.80^{* * *}$ \\
\hline$a$ (Wei) & -0.02 & -0.20 & 0.32 & 0.29 & -0.31 & $-0.50^{*}$ & $-0.79^{* * *}$ & -0.36 & $-0.43^{*}$ & 0.32 & $0.57^{* *}$ & $-0.54^{* *}$ \\
\hline$b$ (Wei) & -0.33 & $-0.53^{* *}$ & -0.43 & -0.19 & $0.48^{*}$ & $0.60^{* *}$ & -0.00 & $0.72^{* * *}$ & $0.69^{* * *}$ & $-0.75^{* * *}$ & -0.07 & $0.67^{* * *}$ \\
\hline$c$ (Wei) & -0.37 & -0.25 & -0.19 & 0.27 & -0.08 & -0.05 & -0.15 & -0.01 & -0.00 & 0.37 & -0.34 & -0.12 \\
\hline$d_{g}$ & -0.27 & -0.35 & $-0.53^{*}$ & $-0.42^{*}$ & $0.65^{* *}$ & 1.00 & & & & & & \\
\hline$\sigma_{g}$ & -0.11 & 0.04 & -0.40 & -0.27 & 0.26 & -0.40 & 1.00 & & & & & \\
\hline$D_{50}$ & -0.33 & -0.37 & $-0.53^{*}$ & -0.29 & $0.63^{* *}$ & $0.97^{* * *}$ & 0.25 & 1.00 & & & & \\
\hline$D_{60}$ & -0.35 & -0.34 & $-0.61^{* *}$ & -0.28 & $0.63^{* *}$ & $0.97^{* * *}$ & 0.40 & $0.95^{* * *}$ & 1.00 & & & \\
\hline Clay & 0.18 & 0.33 & $0.51^{* *}$ & $0.44^{*}$ & $-0.61^{* *}$ & $-0.82^{* * *}$ & -0.32 & $-0.76^{* * *}$ & $-0.77^{* * *}$ & 1.00 & & \\
\hline Silt & 0.39 & 0.22 & 0.35 & 0.11 & -0.37 & $-0.54^{* *}$ & -0.36 & $-0.63^{* *}$ & $-0.63^{* *}$ & 0.11 & 1.00 & \\
\hline Sand & -0.34 & -0.38 & $-0.59^{* *}$ & $-0.41^{*}$ & $0.68^{* * *}$ & $0.97^{* * *}$ & $0.43^{*}$ & $0.93^{* * *}$ & $0.94^{* * *}$ & $-0.88^{* * *}$ & $-0.58^{* *}$ & 1.00 \\
\hline
\end{tabular}

"***, and ${ }^{* * *}$ : indicate significant correlation at $P \leq 0.05, P \leq 0.01$, and $P \leq 0.001$, respectively. Soil bulk density $\left(\rho_{b}\right)$, soil total porosity $(\Phi)$, Field saturated soil hydraulic conductivity $\left(K_{f s}\right)$, Mean Weight Diameter of soil aggregates (MWD).

only with silt content (Table 6). The values of $\alpha$ (Fred-4p), $d_{f}$ (Fred-4p), $n$ (Fred-4p), $c$ (ONL), $\mu$ (ONL), $d_{0}$ (AD), $\alpha$ (Fred$3 \mathrm{p}$ ), $n$ (Fred-3p), $c$ (MLG), and $b$ (Wei) correlated positively with soil particle size. These parameters increased with the size of soil particles, while the parameters $a$ (MLG), $b$ (MLG), and $a$ (Wei) decreased with increasing soil particle size. Furthermore, as shown in Table 6 , values of $\alpha$ (Fred-4p), $d_{f}$ (Fred-4p), $c$ (ONL), $\mu$ (ONL), $\delta(\mathrm{ONL}), b_{0}(\mathrm{AD}), \alpha$ (Fred-3p) increased with a widening of the PSD range (as reflected by the standard deviation of the soil particle diameter, $\sigma_{g}$ ). However, $c_{0}$ (AD), $b$ (MLG), and $a$ (Wei) decreased with increasing $\sigma_{g}$ values.

\section{CONCLUSIONS}

In this preliminary study we investigated the feasibility of 19 models to describe measured soil particle-size distributions (PSDs) of 24 different soils in terms of different efficiency criteria. Results indicate that rankings of the model performance differed depending upon the particular efficiency criteria considered. For example, RMSE, MAX, and STDEV values varied widely among the PSD models, which implies that these criteria all represented different aspects of the accuracy of the models. Six models were found to provide the most accurate results: a modified logistic growth function (MLG), Fredlund type models with 3 and 4 parameters (Fred-3p and Fred- $4 p$ ), an Anderson type model (AD), an offset nonrenormalized lognormal function (ONL), and a Weibull type function (Wei). Prediction errors of these models depended on the particle diameter at which the cumulative PSD fraction was estimated. Accu- racies were found to decrease with increasing soil particle diameter. This implies that one should consider the range of sizes of the soil particles for which the model will be used. A model may be acceptable for some range of the particle diameter, or the entire PSD, but not necessarily for other particle sizes. Based on the mean values of the RMSE, MAX, and STDEV, all of the selected models performed significantly better for finetextured soils as compared to coarse-textured soils.

The fitting parameters of selected PSD models showed statistically significant correlations with several soil quality indices such as $K_{f s}$, MWD, soil porosity, and soil bulk density. These results may be used to advantage in future studies to derive more accurate pedotransfer functions (PTFs) for estimating the unsaturated soil hydraulic properties and/or related soil physical parameters from PSD data. Still, we acknowledge that the number of soil samples $(n=24)$ used in this study is not sufficient to draw strong conclusions. A similar analysis as followed herein, but with a much larger soils database, may be needed to obtain more definite conclusions.

Acknowledgements. This work was supported by the Iran National Science Foundation [grant No. 91002216] and Urmia University [grant No. 93/K/023].

\section{REFERENCES}

Andersson, S., 1990. Markfysikaliska undersokningar I odlad jord, XXVI. Om mineraljordens och mullens rumsutfyllande egenskaper. En Teoretisk Studie. Swedish University of 
Agricultural Sciences, Uppsala, Sweden. (In Swedish.)

Arya, L.M., Paris, J.F., 1981. A physicoempirical model to predict the soil moisture characteristic from particle-size distribution and bulk density data. Soil Sci. Soc. Am., J., 45, 6, 1023-1030.

Assouline, S., Tessier, D., Bruand, A., 1998. A conceptual model of the soil water retention curve. Water Resour. Res., 34, 223-231.

Bagarello, V., Provenzano, G., Sgroi, A., 2009. Fitting particle size distribution models to data from Burundian soils for the BEST procedure and other purposes. Biosyst Eng., 104, 435-441.

Bah, AR., Kravchuk, O., Kirchhof, G., 2009. Fitting performance of particle-size distribution models on data derived by conventional and laser diffraction techniques. Soil Sci. Soc. Am. J., 73, 1101-1107.

Banaei, M.H., 1998. Soil moisture and temperature regime map of Iran. Soil and Water Research Institute, Ministry of Agriculture, Iran.

Bayat, H., Rastho, M., Zadeh, M.M., Vereecken, H., 2015. Particle size distribution models, their characteristics and fitting capability. J. Hydrol., 529, 872-889.

Beke, G., Lindwall, C., Entz, T., Channappa, T., 1989. Sediment and runoff watercharacteristics as influenced by cropping and tillage practices. Can. J. Soil Sci., 69, 3, 639-647.

Bird, N.R.A., Perrier, E., Rieu, M., 2000. The water retention function for a model of soil structure with pore and solid fractal distributions. Eur. J. Soil Sci., 51, 55-63.

Bittelli, M., Campbell, G.S., Flury, M., 1999. Characterization of particle-size distribution in soils with a fragmentation model. Soil Sci. Soc. Am. J., 63, 782-788.

Blake, G.R., Hartge, K.H., 1986. Bulk density. In: Klute, A. (Ed.): Methods of Soil Analysis. Part 1. 2nd Ed. Agron. Monogr. 9. ASA. Madison. WI. 375 p.

Bolster, C.H., Hornberger, G.M., 2007. On the use of linearized Langmuir equations. Soil Sci. Soc. Am. J., 71, 1796-1806.

Botula, Y.D., Cornelis, W.M., Baert, G., Mafuka, P., Van Ranst, E., 2013. Particle size distribution models for soils of the humid tropics. J. Soils Sed., 13, 686-698.

Buchan, G.D., 1989. Applicability of the simple lognormal model to particle-size distribution in soils. Soil Sci., 147, 155-161.

Buchan, G.D., Grewal, K.S., Robson, A.B., 1993. Improved models of particle- size distribution: An illustration of model comparison techniques. Soil Sci. Soc. Am. J., 57, 901-908.

Carsel, R.F., Parrish, R.S., 1988. Developing joint probability distributions of soil water retention characteristics. Water Resour. Res., 24, 755-769.

Chapuis, R.P., 2012. Predicting the saturated hydraulic conductivity of soils: a review. Bull Eng Geol Environ., 71, 401434.

Ersahin, S., Gunal, H., Kutlu, T., Yetgin, B., Coban, S., 2006. Estimating specific surface area and cation exchange capacity in soils using fractal dimension of particle size distribution. Geoderma, 136, 3, 588-597.

Fredlund, M.D., Fredlund, D.G., Wilson, G.W., 2000. An equation to represent grain-size distribution. Can. Geotech. J., 37, 817-827.

Gee, G.W., Or, D., 2002. Particle-size analysis. In: Dane, J.H., Topp, G.C. (Eds.): Methods of Soil Analysis. Part 4. SSSA Book Series No. 5. SSSA, Madison, WI. pp. 255-293.

Ghorbani Dashtaki, S., Homaee, M., Khodaverdiloo, H., 2010. Derivation and validation of pedotransfer functions for estimating soil water retention curve using a variety of soil data. Soil Use Manage., 26, 68-74.
Ghorbani-Dashtaki, S., Homaee, M., Loiskandl, W., 2016. Towards using pedotransfer functions for estimating infiltration parameters. Hydrol. Sci. J., 61, 1477-1488. DOI: 10.1080/02626667.2015.1031763.

Gimenez, D., Rawls, W.J., Pachepsky, Y., Watt, J.P.C., 2001. Prediction of a pore distribution factor from soil textural and mechanical parameters. Soil Sci., 166, 79-88.

Haverkamp, R., Parlange, J.Y., 1986. Predicting the water retention curve from a particle size distribution: 1. Sandy soils without organic matter. Soil Sci., 142, 325-339.

Hwang, S.I., 2004. Effect of texture on the performance of soil particle size distribution models. Geoderma, 123, 363-371.

Hwang, S.I., Powers, S.E., 2003. Using particle-size distribution models to estimate soil hydraulic properties. Soil Sci. Soc. Am. J., 67, 1103-1112.

Hwang, S.I., Lee, K.P., Lee, D.S., Powers, S.E., 2002. Models for estimating soil particle-size distributions. Soil Sci. Soc. Am. J., 66, 1143-1150.

Jabro, J.D., 1992. Estimation of saturated hydraulic conductivity of soils from particle size distribution and bulk density data. Am. Soc. Agric. Eng., 35, 557-560.

Jaky, J., 1944. Soil Mechanics. Egyetemi Nyomada, Budapest, Hungary.

Khodaverdiloo, H., Samadi, A., 2011. Batch equilibrium study on sorption, desorption, and immobilization of cadmium in some semiarid-zone soils as affected by soil properties. Soil Res., 49, 5, 444-454.

Khodaverdiloo, H., Homaee, M., Van Genuchten, M.T., Ghorbani Dashtaki, S., 2011. Deriving and validating pedotransfer functions for some calcareous soils. J. Hydrol., 399, 93-99.

Kolev, B., Rousseva, S., Dimitrov, D., 1996. Derivation of soil water capacity parameters from standard soil texture information for Bulgarian soils. Ecol. Model., 84, 315-319.

Krause, P., Boyle, D.P., Bäse, F., 2005. Comparison of different efficiency criteria for hydrological model assessment. Adv Geosci., 5, 89-97.

Lassabatère, L., Angulo-Jaramillo, R., Soria Ugalde, J.M, Cuenca, R., Braud, I., Haverkamp, R., 2006. Beerkan estimation of soil transfer parameters through infiltration experiments - BEST. Soil Sci. Soc. Am. J., 70, 521-532.

Liao, K., Xu, S., Zhu, Q., 2015. Development of ensemble pedotransfer functions for cation exchange capacity of soils of Qingdao in China. Soil Use Manag., 31, 483-490.

Liu, J., Xu, S., Liu, H., 2003. Investigation of different models to describe soil particle- size distribution data. Adv. Water Sci., 14, 588-592.

Liu, J., Xu, S., Liu, H., Guo, F., 2004. Application of parametric models to description of particle-size distribution in loamy soils. Acta Pedologica Sinica, 41, 375-379.

Manrique, L.A., Jones, C.A., Dyke, P.T., 1991. Predicting cation exchange capacity from soil physical and chemical properties. Soil Sci. Soc. Am. J., 55, 787-794.

Mbonimpa, M., Aubertin, M., Chapuis, R.P., Bussiere, B., 2002. Practical pedotransfer functions for estimating the saturated hydraulic conductivity. Geotech. Geol. Eng., 20, 235259.

Nemes, A., Wosten, J.H.M., Lilly, A., Voshaar, J.H.O., 1999. Evaluation of different procedures to interpolate particle-size distributions to achieve compatibility within soil databases. Geoderma, 90, 187-202.

Nemes, A., Schaap, M.G., Wösten, J.H.M., 2003. Functional evaluation of pedotransfer functions derived from different scales of data collection. Soil Sci. Soc. Am. J., 67, 10931102. 
Parchami-Araghi, F., Mirlatifi, S.M., GhorbaniDashtaki, S., Mahdian, M.H., 2013. Point estimation of soil water infiltration process using Artificial Neural Networks for some calcareous soils. J. Hydrol., 481, 35-47.

Patil, N.G., Singh, S.K., 2016. Pedotransfer functions for estimating soil hydraulic properties: A review. Pedosphere, 26, 4, 417-430.

Razzaghi, S., Khodaverdiloo, H., Dashtaki, S.G., 2016. Effects of long-term wastewater irrigation on soil physical properties and performance of selected infiltration models in a semi-arid region. Hydrol. Sci. J., 61, 10, 1778-1790.

Saxton, K.E., Rawls, W.J., Romberger, J.S., Pependick, R.I., 1986. Estimating generalized soil water characteristics from soil texture. Soil Sci. Soc. Am. J., 55, 1231-1238.

Shangguan, W., Yongjiu, D., Gutierrez, C.G., Yuan, H., 2014. Particle-size distribution models for the conversion of Chinese data to FAO/USDA system. Sci. World J. DOI: $10.1155 / 2014 / 109310$.

Shiozawa, S., Campbell, G.S., 1991. On the calculation of mean particle diameter and standard deviation from sand, silt, and clay fractions. Soil Sci., 152, 427-431.

Shirazi, M.A., Boersma, L., 1984. A unifying quantitative analysis of soil texture. Soil Sci. Soc. Am. J., 48, 142-147.

Shirazi, M.A., Hart, J.W., Boersma, L., 1988. A unifying quantitative analysis of soil texture: improvement of precision and extension of scale. Soil Sci. Soc. Am. J., 52, 1, 181-190.
Skaggs, T.H., Arya, L.M., Shouse, P.J., Mohanty, B.P., 2001. Estimating particle size distribution from limited soil texture data. Soil Sci. Soc. Am. J., 65, 1038-1044.

Tyler, S.W., Wheatcraft, S.W, 1992. Fractal scaling of soil particle-size distributions: analysis and limitations. Soil Sci. Soc. Am. J., 56, 362-369.

Vipulanandan, C., Ozgurel, H.G., 2009. Simplified relationships for particle-size distribution and permeation groutability limits for soils. J. Geotech. Geoenviron. Eng., 135, 11901197.

Willmott, C.J., 1981. On the validation of models. Phys. Geogr. 2, 184-194.

Xu, G., Li, Z., Li, P., 2013. Fractal features of soil particle-size distribution and total soil nitrogen distribution in a typical watershed in the source area of the middle Dan River, China. Catena, 101, 17-23.

Zhao, P., Shao, M., Horton, R., 2011. Performance of soil particle-size distribution models for describing deposited soils adjacent to constructed dams in the China loess plateau. Acta Geophysica, 59, 124-138.

Zhuang, J., Jin, Y., Miyazaki, T., 2001. Estimating water retention characteristic from soil particle-size distribution using a non-similar media concept. Soil Sci., 166, 308-321.

Received 28 June 2017 Accepted 19 October 2017 